Dom. Cien., ISSN: 2477-8818

Vol. 5, núm.1., ene, 2019, pp. 751-758

\title{
Factores epidemiológicos asociados a dengue en pacientes adultos
}

\author{
Epidemiological factors associated with dengue in adult patients
}

\section{Fatores epidemiológicos associados à dengue em pacientes adultos}

Recibido: 27 de noviembre de 2018 * Corregido: 18 de diciembre de $2018 *$ Aceptado: 20 de diciembre de 2018

I. Especialista en Gerencia y Planificación Estratégica en Salud; Diploma Superior de Cuarto Nivel en Desarrollo Local y Salud; Especialista en Cirugía General; Doctor en Medicina y Cirugía; Universidad de Guayaquil, Guayaquil, Ecuador.

II. Magister en Salud Publica; Magister en Nutrición; Especialista en Cirugía General; Doctor en Medicina y Cirugía; Universidad de Guayaquil, Guayaquil, Ecuador.

III. Magister en Gerencia en Salud para el Desarrollo Local; Diploma Superior en Desarrollo Local y Salud; Magister en Epidemiologia; Diploma Superior en Enfermedades Inmunodeficientes en VIH-Sida; Magister en Medicina Tropical; Doctor en Medicina y Cirugía; Universidad de Guayaquil, Guayaquil, Ecuador. 


\title{
Resumen
}

En el presente trabajo de investigación se indaga sobre los factores epidemiológicos asociados a dengue en pacientes adultos. Primero hay que aclarar que el dengue es una enfermedad viral aguda transmitida a través de la picadura del mosquito (artrópodo) Aedes aegypti infectado con cualquiera de los serotipos de virus dengue. Se tiene que resaltar que las características climatológicas, poblacionales, económicas y sociales, contribuyen a la proliferación del mosquito Aedes aegypti principal vector de esta enfermedad. Entre sus formas de expresarse se encuentran desde: la fiebre indiferenciada (frecuente en niños) y fiebre con cefalea, gran malestar general, dolores osteomioarticulares, con o sin exantema, leucopenia o algún tipo de sangrado. Se obtuvo como resultado que el curso de la enfermedad pasa por tres etapas clínicas: la etapa febril la única para la inmensa mayoría de los enfermos la etapa crítica y la etapa de recuperación. Se puede decir que este virus es un problema de salud pública por lo que se pudo concluir que las medidas de prevención están relacionadas con el control del vector, tales como evitar los criaderos destruyendo los recipientes de agua inservibles así como cubriendo y protegiendo los recipientes de agua para el consumo, entre otras medidas.

Palabras claves: Dengue, adulto, mosquito, virus y criadero.

\begin{abstract}
In the present research work is investigated on the epidemiological factors associated with dengue in adult patients. First, it must be clarified that dengue is an acute viral disease transmitted through the bite of the mosquito (arthropod) Aedes aegypti infected with any of the serotypes of dengue virus. It must be emphasized that the climatic, population, economic and social characteristics contribute to the proliferation of the Aedes aegypti mosquito, the main vector of this disease. Among their ways of expressing themselves are: undifferentiated fever (frequent in children) and fever with headache, great malaise, osteomyoarticular pain, with or without rash, leukopenia or some type of bleeding. The result was that the course of the disease goes through three clinical stages: the febrile stage is the only one for the immense majority of the patients at the critical stage and the recovery stage. It can be said that this virus is a public health problem so it could be concluded that prevention measures are related to the control of the vector, such as avoiding hatcheries by destroying unusable
\end{abstract}


water containers as well as covering and protecting containers of water for consumption, among other measures.

Key words: Dengue, adult, mosquito, virus and hatchery.

\section{Resumo}

$\mathrm{Na}$ presente pesquisa, investigamos os fatores epidemiológicos associados à dengue em pacientes adultos. Primeiramente, deve-se esclarecer que a dengue é uma doença viral aguda transmitida pela picada do mosquito Aedes aegypti infectado com qualquer um dos sorotipos do vírus da dengue. Deve-se ressaltar que as características climáticas, populacionais, econômicas e sociais contribuem para a proliferação do mosquito Aedes aegypti, principal vetor desta doença. Entre suas formas de expressão estão: febre indiferenciada (freqüente em crianças) e febre com cefaleia, grande mal-estar, dor osteomioarticular, com ou sem erupção cutânea, leucopenia ou algum tipo de sangramento. $\mathrm{O}$ resultado foi que o curso da doença passa por três estágios clínicos: o estágio febril é o único para a imensa maioria dos pacientes no estágio crítico e no estágio de recuperação. Pode-se dizer que este vírus é um problema de saúde pública, portanto, pode-se concluir que as medidas de prevenção estão relacionadas ao controle do vetor, como evitar incubatórios destruindo recipientes de água inutilizáveis e cobrindo e protegendo recipientes de água para consumo, entre outras medidas.

Palavras chave: Dengue, adulto, mosquito, vírus e incubatório.

\section{Introducción.}

El dengue es una enfermedad viral aguda transmitida a través de la picadura del mosquito (artrópodo) Aedes aegypti infectado con cualquiera de los serotipos de virus dengue. Son virus envueltos, de 40 a $50 \mathrm{~nm}$ de diámetro, con cápside icosaédrica y genoma de ácido ribonucleico (ARN) monocatenario, no segmentado, de polaridad positiva perteneciente al género flavivirus de la familia Flaviviridae (Real-Cotto, Regato, Burgos, \& Jurado, 2017).

Existen cuatro serotipos denominados DENV1, DENV2, DENV3 y DENV 4, cualquiera de ellos puede producir las formas graves de la enfermedad, aunque los serotipos 2 y 3 han estado asociados a la 
mayor cantidad de casos graves y fallecidos (Martínez, 2008). Las características climatológicas, poblacionales, económicas y sociales, contribuyen a la proliferación del mosquito Aedes aegypti principal vector de esta enfermedad. Dada la tasa de letalidad y la incidencia acumulada o número de casos que se reportan cada año, el dengue se ha convertido en un problema de salud pública. Por lo tanto, la demanda de atención es permanente en los establecimientos de salud y como se trata de un evento que puede presentarse de forma asintomática o como forma grave, amerita seguimiento y monitoreo permanente para evitar futuras complicaciones (Ministerio de salud pública República Dominicana, 2010).

En Ecuador, en 1988, se produjo el primer brote epidémico de Dengue Clásico serotipo 1 en la ciudad de Guayaquil, con un estimado de 600.000 casos, a partir de entonces, todas las provincias del litoral, de la Amazonia y valles subtropicales de la Sierra, han sido afectados por brotes epidémicos de diversa magnitud. El mosquito Aedes aegypti, transmisor del virus del dengue, se encuentra diseminado en toda la ciudad de Guayaquil, los índices se encuentran actualmente por encima del $20 \%$ en casi todas las parroquias de la urbe. (Zavala, 2012).

El virus del dengue tiene diversas formas de expresión clínica: desde fiebre indiferenciada (frecuente en niños) y fiebre con cefalea, gran malestar general, dolores osteomioarticulares, con o sin exantema, leucopenia y algún tipo de sangrado hasta formas graves que habiendo comenzado con lo anterior presenta choque hipovolémico por extravasación de plasma, con trombocitopenia moderada o intensa y con grandes hemorragias en aparato digestivo y otras localizaciones. También el dengue es capaz de expresarse mediante las llamadas formas "atípicas" que son relativamente infrecuentes y resultan de la afectación particularmente intensa de un órgano o sistema: encefalopatía, miocardiopatía o hepatopatía por dengue, entre otras (Martínez, 2008).

La inmunidad que deja la infección por cada serotipo viral es duradera, probablemente de por vida y se expresa por la presencia de anticuerpos (Ac) neutralizantes hemotípicos. No existe inmunidad cruzada de serotipos, excepto durante las primeras semanas o meses después de la infección. Sin embargo, cuando una 
persona tiene Ac subneutralizantes contra uno de los virus del dengue y es infectado por otro serotipo viral se produce una respuesta infrecuente, casi exclusiva de la infección por dengue: una amplificación dependiente de anticuerpos (ADA) que se traduce en una elevada replicación viral y aumento de la viremia, lo cual condiciona y favorece el desarrollo la forma grave de la enfermedad (Martínez, 2008).

La Organización Mundial de la Salud (OMS) está promoviendo el control integrado de vectores, incluyendo medidas alternativas como el control biológico o el manejo ambiental, en el tiempo y lugar donde ellas sean efectivas y aplicables. También impulsa el uso de insecticidas cuando el control biológico no es una alternativa. En tal sentido, los insecticidas continúan siendo un elemento vital en programas de control. Sin embargo, existe una importante habilidad de las poblaciones de insectos para desarrollar resistencia a varias clases de insecticidas que se han usado (Zavala, 2012).

El Aedes aegypti es un mosquito doméstico o peridoméstico cuya hembra precisa de la sangre humana para mantener su reproducción; que pone sus huevos en depósitos de agua limpia o semi-limpia. Los huevos se convierten en larvas y posteriormente en pupas hasta emerger en forma adulta. La hembra infectante puede vivir hasta dos meses y picar varias veces al día. Otros mosquitos también han demostrado su competencia vectorial, como el Aedes albopictus llamado "el tigre asiático" que fue llevado a América hace dos décadas y actualmente infecta varios países en Europa. (Martínez, 2008).

\section{Materiales y métodos}

La técnica de metodológica que se utilizó para el siguiente estudio fue la investigación documental. Este método consiste en un procedimiento científico, un proceso sistemático de indagación, recolección, organización, análisis e interpretación de información o datos en torno a un determinado tema. Al igual que otros tipos de investigación, éste es conducente a la construcción de conocimientos (Alfonzo, 1994).

\footnotetext{
\begin{tabular}{l|l}
755 & Vol. 5, núm. 1, enero 2019, pp. 751-758 \\
Hugo A. Luna-Rodríguez; Glubis W. Gomez-Pelaez; Wilson W. Cando-Caluña
\end{tabular}
} 
También se puede definir como un proceso basado en la búsqueda, recuperación, análisis, crítica e interpretación de datos secundarios, es decir, los obtenidos y registrados por los otros investigadores en fuentes documentales: impresas, audiovisuales o electrónicas. (Arias., 2006).

El presente estudio se recopiló información de diversos estudios médicos en referencia al virus del dengue. Además de estadísticas de la Organización Mundial de la Salud y sus afiliados. Los criterios fue discriminar los datos dándole prioridad a los estudios más recientes y completos referentes los factores epidemiológicos asociados a dengue en pacientes adultos.

\section{Resultados}

El dengue es una enfermedad muy dinámica, a pesar de ser de corta duración. Su expresión puede modificarse con el paso de los días y puede también agravar de manera súbita, por lo cual el enfermo necesita que el medico lo atienda de modo repetido, preferentemente todos los días. El curso de la enfermedad del dengue pasa por tres etapas clínicas: la etapa febril la única para la inmensa mayoría de los enfermos la etapa crítica y la etapa de recuperación (Martínez, 2008).

La nueva generación de programas de prevención y control del dengue en América respalda las acciones encaminadas a lograr la adecuada vigilancia y el control de la transmisión con un enfoque ecosistémico. Esto significa que se sabe bien lo que hay que hacer; el reto consiste en hacerlo de forma integrada y sostenible. Sin embargo, en la gran mayoría de los países de la región aún no se aplican a cabalidad estos principios y no se cuenta con programas de control preventivo, integrado y sustentable (Kourí, 2011).

La enfermedad no se transmite de persona a persona, ni a través de objetos, ni por vía oral, respiratoria ni sexual. Sin embargo, aunque es infrecuente, también están descriptas la transmisión durante el embarazo y la vía transfusional. (Ministerio de Salud de la Nación de Argentina, 2015). 


\section{Conclusiones.}

Es importante destacar que la problemática de dengue no solo debe estudiársela por el virus causante de la enfermedad, sino que existen otros elementos como: el vector transmisor, las personas susceptibles, factores ambientales condicionantes, entre otros. Esto limita a este estudio a valorarlo de manera integral. (Real-Cotto, Regato, Burgos, \& Jurado, 2017).

Las medidas de prevención están relacionadas con el control del vector: evitar los criaderos destruyendo los recipientes de agua inservibles (neumáticos usados, latas, botellas, etc), así como cubriendo y protegiendo los recipientes de agua para el consumo (tanques y otras vasijas), modificar el cultivo de plantas en recipientes con agua a los cuales puede echárseles arena o tierra, y evitar aguas estancadas peridomiciliares. (Martínez, 2008)

Al revisar la situación epidemiológica de los años estudiados, se demuestra que existe la circulación de los 4 serotipos de virus dengue en el Ecuador, observándose la presencia de algún serotipo en la mayoría de las provincias; y ante la circulación de serotipos de virus diferentes o la reaparición de virus que habían circulado anteriormente, como los virus DEN1, DEN2 y DEN4 a la vez, han puesto en riesgo a la población de sufrir la enfermedad en sus diversas formas, en los últimos años. (Real-Cotto, Regato, Burgos, \& Jurado, 2017).

\section{Recomendaciones.}

La participación comunitaria en esta tarea es esencial y aunque la responsabilidad debe mantenerse en las manos de las autoridades sanitarias, debe lograrse una amplia participación de todas las instancias, desde los jefes de estado hasta los estratos sociales más alejados del poder. Si bien los ministerios de salud deben desempeñar un papel determinante en las actividades de orientación, la educación de la población y el control de los programas nacionales, es preciso insistir en que la participación responsable de la comunidad

\footnotetext{
\begin{tabular}{l|l}
757 & Vol. 5, núm. 1, enero 2019, pp. 751-758 \\
Hugo A. Luna-Rodríguez; Glubis W. Gomez-Pelaez; Wilson W. Cando-Caluña
\end{tabular}
} 
puede y debe contribuir a eliminar los principales criaderos del vector, ya que están ligados al hábitat del ser humano y son producto de su actividad. (Kourí, 2011).

Al no existir la vacuna, la única forma de controlar la enfermedad es prevenirla. Las mejores medidas de prevención son: $\bullet$ El control del mosquito y sus criaderos $\bullet$ La detección rápida y temprana de los casos mediante la vigilancia de síndromes febriles inespecíficos. • El aislamiento entomológico (protección de las picaduras) de los pacientes enfermos de dengue mientras se encuentren febriles. Hay acciones simples y económicas que pueden ayudar al control de los mosquitos sin utilizar productos químicos. (Ministerio de Salud de la Nación de Argentina, 2015).

\section{Bibliografía.}

Alfonzo, I. (1994). . Técnicas de investigación bibliográfica. . Caracas: Contexto Ediciones.

Arias., F. G. (2006). El proyecto de investigación. Caracas: Episteme.

Kourí, G. (2011). El dengue, un problema creciente de salud en las Américas. Rev Cubana Salud Pública, 5461.

Martínez, E. (2008). Dengue. Estudos Avançados, 33-49.

Ministerio de Salud de la Nación de Argentina. (2015). Dengue . Guía para el equipo de salud, 1-12.

Ministerio de salud pública República Dominicana. (2010). Guía para el manejo clinico del Dengue. Guía para el manejo clinico del Dengue, 7-14.

Real-Cotto, J., Regato, M., Burgos, V., \& Jurado, E. (2017). Evolución del virus dengue en el Ecuador. Período 2000 a 2015. An Fac med., 29-35.

Zavala, T. (30 de mayo de 2012). Secretaría de educación superior, ciencia, tecnologia e innovación. Obtenido de Secretaría de educación superior, ciencia, tecnologia e innovación: http://repositorio.educacionsuperior.gob.ec/bitstream/28000/991/1/T-SENESCYT-0395.pdf 